\title{
Passenger Transport Management Methodology Based on the Econometric Analysis of Demand for Trans-Regional Transportation in Respect to the Innovation Economic Development Stage
}

\author{
Maria Olegovna Suraeva ${ }^{1}$, Maria Ivanovna Abuzyarova ${ }^{2}$, Rustam Idrisovich Khansevyarov ${ }^{1} \&$ Aleksandr \\ Petrovich Zhabin ${ }^{1}$ \\ ${ }^{1}$ Associate Professor of The department of Management, Doctor of Economics, Samara State University of \\ Economics, Samara, Russian Federation \\ 2 Associate Professor of The department of Management, Candidate of Economic Sciences, Samara State \\ University of Economics, Samara, Russian Federation \\ Correspondence: Suraeva Maria Olegovna, Associate Professor of The department of Management, Doctor of \\ Economics, Samara State University of Economics, Samara, Russian Federation. E-mail: \\ marusyasuraeva@mail.ru
}

Received: December 15, 2014

Accepted: December 29, 2014

Online Published: March 25, 2015

doi:10.5539/mas.v9n5p177

URL: http://dx.doi.org/10.5539/mas.v9n5p177

\begin{abstract}
Transport complex is one of the fields of the RF forming infrastructure economy, which state influences national economy branches complexes development, interrelation of the economy branches, industry branches, and territorial complexes.

On the one hand, transport as a market segment carries out goods exchange and renders services to population, and, on the other hand -as a market entity, it sells its services by transferring goods and passengers. Different kinds of transport render these services differently, thereby forming transport market. The development of transport is attributed to the growth of any country's productive forces and its external relations.

Complexity and low development level of formation and strategy realization problem of railway passenger transportation management, as well as need for further deepening the theory and practice of its prospects for development predetermined the topic choice and relevance in respect to the innovation stage of the Russian economy development.

The methodology of demand for trans-regional railway passenger transportation in the RF and its main parameters depending on various economic factors based on author econometric model is developed.
\end{abstract}

Keywords: supply, demand, passenger transportation, innovations, trans-regional transports, innovation-driven economy

\section{Introduction}

New passenger transportation management economic mechanism should include price strategy, win-win relations between railways, state, regional administration, and transportation services receivers.

The reduction in the volume of transportation activity caused the need for search and development of new effective passenger transportation management economic mechanism.

The strategic analysis of passenger railroad transport activity made it possible to identify a complex of fundamental problems to be solved with the participation of the state and private sector.

The main problem is running unprofitable passenger transportation and high rate of rolling stock wear and obsolescence. Another system problem is incompleteness of institutional framework of the branch (Elizarev, Y. V. \& Gorbunova, M. A.).

Existing economic model of the branch is marked by the gap between fares level and price rises in economy and funding socially important passenger services at the expense of freights services that led to the high rate of assets wear.

One of main tasks provided by the economic strategy of the Russian Federation for the forthcoming decade is to 
achieve stable economic growth by means of forced industrialization.

For this purpose it is necessary to adopt innovation into logistics and service system, transportation services, form transport services line-up with guarantee delivery time, broad logistic services range and develop appropriate infrastructure, establish flexible competitive tariffs, renew and change rolling stock structure, and establish national railway engineering branch (Suraeva, M. O., 2014).

Passenger transportation in the Russian Federation has the significant potential to turn itself into commercially effective and profitable business in case of institutional environment improving and new approaches introducing in transport marketing and logistics on the part of leading world companies. Realization of this strategy will allow forming effective passenger complex characterized by the high service level and service availability.

During the study it has been established that existing works on passenger transportation theory almost completely disregarded the issues of price elasticity of demand for transport service since fare in this transportation mode made a small minority of per capita income.

It is possible to claim that market demand was so high that any event regarding transport management was covered with this demand. At this point another problem was being solved -passenger transportation services deficit elimination at the solution of which main efforts of researchers and experts were directed to.

In the West researchers in the field of passenger transport management are concerned with the problem of demand analysis and social mobility, which in underpopulated cities with long distances between the centres of attraction makes from $0 \%$ to $14 \%$ in total population movement (Office of rail regulation, Promoting safety and value in Britain's railways: our strategy for 2009-2014).

Russia experiences situation when deregulated (or partially regulated) passenger transport market provides services to population for which the cost of transport makes a substantial share of expenses for one reason or another.

In order to provide complete and qualitative satisfaction of population's and economy's wants in transport the state is concerned with the development of the following main criteria of branch functioning:

- Train system safety, which requires clear regulation of transport process' all participants' activities in accordance with national standards, which in turn should be relevant, and regularly amended taking into account scientific and technical progress' requirements;

- Special-purpose financing - as far as the state is one of the main sources of passenger transportation financing, it is interested in complete and proper use of taxpayers' money;

- Branch performance maximization - taking into account branch fragmentation and private initiative uprising, distinct coordination of market agents' actions for complete and timely satisfaction of economy's and populations' wants in transportation is necessary;

- Strategy planning and development - as a main market player and infrastructure owner the state needs clear vision of the branch future development to meet the growing needs of economy and population along with set growth indexes achievement;

- Carrying out of socially important, but low-gain researches - given that private sector finances researches of quick outcome and minor risk, other more risky and long-term projects of possible important nationwide scale may be put on the back burner (Macheret, D. A.).

- As the analysis showed, the existing national policy in the field of railroad transport didn't meet set target regarding rendered services quality improvement, branch main assets' modernization and effective cooperation between public and private sector;

- Transporters are de-stimulated with the principle of state funding, which covers only their minimum losses of profitability, thereby the level of allocated subsidies covers only the half of all losses;

- Backlog of demand for transportation on the part of population primarily requires carriages deficit solution, which transporters fail to solve at their own expense. Given this, there are no incentives in the form of long-term agreements, necessary profitability of activity or allowance for pecuniary institutions financing;

- Passenger transportation arrangement agreements are concluded for short period (1 year with a further 3 years extension) that in such capital intensive sector as railroad transport is not enough to execute transporters' minimum plans to reach profitable level of services and implement long-term investment programs;

- Passengers' interests fail to appear priority in agreements with transporters, since their monitoring is 
provided using transporters' performance consolidated indicators (trains running frequency and average number of train carriages). Given this, such important for users indicators, as safety, schedule accuracy and transportation amenities are missing;

- Level of competition for a right to carry out passenger transportation can be reduced by means of requirement toughening regarding availability of own cars fleet, and, subsequently, locomotives (Kolpakov, V. S., Shubko, V. G., 2003).

International practices prove there is no general standard for railway branch reforming and development (IBM Global Business Services, Humboldt University (Germany, 2007).

The above mentioned requires scientific substantiation of the economic nature of the passenger transportation process in Russia, this process' quality and effectiveness improvement based on new methodical techniques and control tools in respect to the innovation stage of economic development.

\section{Materials and Methods}

\subsection{Development of Main Parameters of Demand for Railway Passenger Transportation}

For the purpose of increasing economic efficiency of passenger transportation, we offer methodology, wherein the model of management enhancement is developed (Figure 1), the matters of passenger complex integration in unified system to the effect of maximum profit-making are studied.

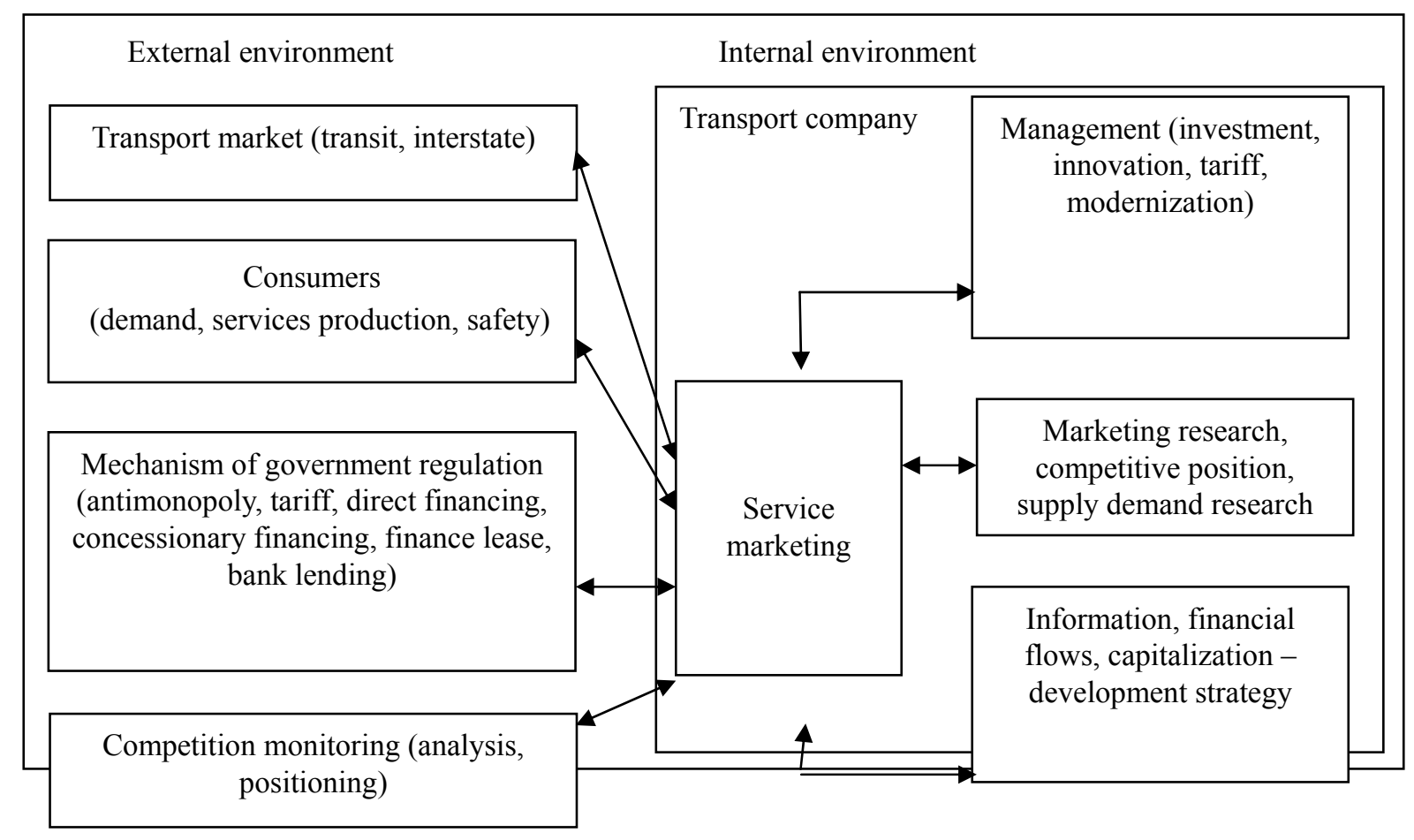

Figure 1. Transport services management model

The new in the arrangement of railroad transport work in the modern context is basic finance indicators planning carried out by means of target profit method (Tiverosky, V. I., 2013).

Let us examine several aspects concerning passenger transportation reorganization.

We offer three functional models of passenger transportation, each of which provides different degree of government intervention into company's internal affairs and different degree of private funds involvement with the following change of company's structure.

The first is a "classic" model, which cooperates with state on a contractual basis according to approved business plan. Given this, state allocates partial investment support regarding its losses. Business plan should be shaped based on bilateral discussions (public authorities and company's managers) and should include all production optimization events. 
The second model - "concession" - involves company transfer to concession for a long term based on concession contract, which claims the availability of scientifically founded business plan, improvement in transportation services quality, rolling stock renewal, transportation volume maintaining, etc. as requirements to potential concessionary. This model will allow increasing company's profits.

The third model -"franchise sale" - involves separate company establishing -a rolling stock owner. Sale of a right to effect passenger transportation across territories and directions is realized by means of tender, preferred bidder which will be a company offering minimal volume of government allowance.

The winner acquires exclusive rights to service territory or route for a specified term.

To provide transparency the amount of allowances has tightly earmarked character and directly depends on the passenger turnover specific route. Subsequently, it is possible to create new promising and decrease unprofitable routes at the expense of management companies' expenditure optimization. Private passenger companies enjoy greater freedom to choose management techniques from.

All free examined models are based on the idea of commercialization that involves internal changes of a company, particularly, changes in HR policy.

The models are interrelated and sequent, i.e. the realization of the first one supposes the transition to the second one, more commercialized and providing greater involvement of private funds, but retaining the right for government allowances considering strategic importance of the given branch development.

Within the framework of the first and second models the tough vertical management structure of a company as a backer of increase in profits and financial stability is suggested.

As it clear from the abovementioned the offered models primarily differ by the degree of government intervention into company's internal affairs, which represent the degree of passenger transportation investment support and funding.

From this standpoint the third model -"franchise sale" - is the most attractive one. Its advantage is not only possibly minimum state allowances, but challenging competition between private companies on the railroad transportation market.

Nonetheless, when introducing this model the process of mutual relations regulation between the state and potential franchises' owners for the purpose of passengers' rights impairment prevention is made difficult. It requires from a public authority the development of strong legal status to provide financial expenditure transparency and consumer protection.

Certainly, the offered program cannot be considered the only possible strategy of passenger transportation development.

Nonetheless, its study is of certain interest as an attempt to overcome the crisis and search for new ways to develop one of the most significant strategic branches of Russia.

The activity of passenger sector of railway transport doesn't allow cardinal solving the problem of discrepancy between the level of service and scope of services to present-day consumer demand.

Passenger transportation in the Russian Federation has the significant potential to turn itself into commercially effective and profitable business in case of institutional environment improving and new approaches in transport marketing and logistics introduction on the part of leading world companies. Realization of this strategy will allow forming effective passenger complex characterized by the high level of service and availability of services (Elizarev, Y. V.).

The extension of HVA goods transportation segment requires increase in supply on the market of high-technology transport services, since the condition of competitiveness of domestic products with import analogues transfers international requirements to production and logistics performance to our market.

When introducing the offered model of passenger transportation management the necessity for transport logistics centres appears to create flexible system of centralized managerial supervision, to regulate and control the process of passenger transportation provision with necessary material resources.

\subsection{Separate Accounting Expenses for Railway Passenger Transportation}

It is well-known that all transportation expenses are divided into dependent and semi-fixed costs. Dependent costs are costs, which depend directly proportional to transportation volume, and semi-fixed costs do not depend on transportation volume or depend on them so insignificantly that this dependence may be disregarded. 
As far as measures characterize transportation process volume, all dependent costs are distributed among measures. Main expenditure items allocation to measure is determined by dependent costs division into measures of corresponding type of transportation.

The ratio of expenditures per measure to the measure volume is called expenditure rate, which is defined for each measure by the method of allocation and characterizes the dependent net cost of given measure unit.

Expenditure rates provide the basis for many economic problem solutions, because if we know dependent costs per measure unit we can calculate dependent costs for any transportation work since the volume of almost any work can be expressed in the terms of measures' volumes.

In the context of the studied methodology, we name expenditure rate dependent expenditure rate, since it characterizes a share of depending on the flow costs amount, which falls at a measure.

However, apart from dependent expenses, there are semi-fixed costs to be added to dependent expenditure rates when calculating costs for discretionary types of work to assess full costs for corresponding type of work.

Given this, the amount of semi-constant expenditures fluctuates depending on transportation volume in each period under review and share of these expenditures (semi-constant expenditure rate), which fall on each measure and should be defined foe each period using special technique (Arkhangelsky, V. N., 1997; Varian, H. R., 1997; Zamkov, O. O., Tolstopyatenko, A. V., Cheremnyh, Y. N., 2001).

The division of all costs into dependent and semi-constant (independent) parts is one of the important matters for economic studies. It is solved by means of all transportation volume-dependent main expenditures allocation to service measures.

The method of all main expenditure items allocation to service measure and the method of expenditure items overhead division into dependent and semi-fixed allow clearly dividing all costs into dependent and semi-constant parts.

Earnings from transportation activity cover enterprise's direct expenses. Consequently, reduction in allowances subject to all necessary costs for equipment keeping and high-quality passenger service providing is possible only in the case of reconsideration of the method of indirect costs allocation to passenger transportation.

The amount of passenger economy indirect costs is defined on the basis of "The methodology of costs division by transportation type according to the factor balance method of calculation cost" using Russian Railways JSC consolidated balance sheet and "Measures for cargo and passenger transportation cost calculation by haulage types".

The main measures of Russian Railways JSC scope of work for Federalnaya Passazhirskaya Kompaniya JSC ("FPK" JCS) are ton-kilometre gross and locomotive-hours of linear range, which present only a partial picture.

Thus, for example, in order to allocate passenger economy costs it is suggested to take several measures by each types of works (ton-kilometre gross, locomotive-hour of train locomotives, locomotive-hours shunting operations and other).

In addition, passenger transportation ton-kilometre gross accounting raises some questions, namely:

- $\quad$ Regarding passenger carriage taring (by types),

- Regarding source documents filling (locomotive driver's route doesn't reflect train set, types of carriages, their ownership). For example, statistical accounting on this indicator includes both passenger equipment and carriages in ownership of other organizations (mail, central bank carriages, store wagons, cabin car, etc.); luggage carriages are not singled out in accounting. All above-mentioned carriages are registered in locomotive driver's route in the column "first-class carriages, second-class carriages", although only carriages for passenger transportation should be ticked in this column.

That is why it is difficult to estimate actual expenditures, which fall at the transportation of passengers, mail, luggage and others.

To effectively introduce reforms and start railroad transport restructuring "The methodology of division of costs allocated to passenger transportation" was in force, which is a fixing for the aggregate of groups, subgroups and main expenditure items of nomenclatures of algorithms, according to which the division of corresponding groups or subgroups of expenditures is carried out.

For each subgroup of expenditure items and group of expenditure items allocated to passenger transportation, the method of expenditure division into passenger transportation, luggage and freight baggage transportation, mail transportation provides the algorithm for division, according to which all items of a given group or subgroup are 
divided into the transportation of corresponding transportation unit (Kuvatov, M. R., 2003).

However, some main expenditure items may have their own algorithms for division into passenger transportation, luggage and freight baggage transportation, mail transportation distinct from the algorithm of corresponding subgroups (Sklyarenko, V. K., Prudnikov et al., 2009).

The following algorithms for expenditures division into services for transportation are applied:

1) Complete allocation to the certain type of transport unit transportation in passenger service: by the algorithm "complete allocation to the certain type of transport unit" all expenditures by all items of this subgroup are completely allocated either to passenger transportation or luggage and freight baggage transportation, or mail transportation;

2) Allocation in proportion to workload indicators: by the algorithm "allocation in proportion to workload indicators" costs by each items of this subgroup are divided into

- Passenger transportation

- Luggage and freight baggage transportation

- Mail transportation in proportion to three planned indicators values. Given this, three indicators mean consolidated index value by the factor "transport unit" with values: 1 - passenger, 2 - luggage and freight baggage, 3 - mail.

For example, if the indicator "car-mileage in passenger traffic" is set, we have the following:

- $\quad$ First indicator is "passenger carriage-mileage in passenger traffic";

- Second one is "luggage car in passenger traffic";

- $\quad$ Third one is "mail car in passenger traffic", correspondingly.

Thus, if three indicators are set for expenditure subgroup:

- $\quad$ a (for passenger transport),

- $\quad$ b (for luggage and freight baggage) and $\mathbf{c}$ (for mail transport), the coefficients will be the following $\mathrm{d} 1=\mathrm{a} /(\mathrm{a}+\mathrm{b}+\mathrm{c}), \quad \mathrm{d} 2=\mathrm{b} /(\mathrm{a}+\mathrm{b}+\mathrm{c})$ and $1-\mathrm{d} 1-\mathrm{d} 2=\mathrm{c} /(\mathrm{a}+\mathrm{b}+\mathrm{c})$.

This subgroup's expenditure items, which lack their own algorithm for division, are divided into passenger transportation, luggage and freight baggage transportation, and mail transportation by multiplying all cost elements by the found coefficients $\mathrm{d} 1, \mathrm{~d} 2$ и $1-\mathrm{d} 1-\mathrm{d} 2$.

The mentioned algorithm is also effective in case where expenditure item is divided into two services, i.e. in proportion to two values of indicators. In this case, we imply the third indicator value for the third service equal to 0 .

\section{In Proportion to Cost Elements Sum}

As a rule, overhead costs items (subgroups, groups) are allocated according to the third algorithm.

According to this algorithm one or several costs elements to calculate multipliers $\mathrm{d} 1, \mathrm{~d} 2,1-\mathrm{d} 1-\mathrm{d} 2$ are specified. Then all items of the given expense group or subgroup, which have no their own division algorithm, are multiplied by the found coefficients, in the same manner as in the previous algorithm.

To calculate coefficients $\mathrm{d} 1$, d2 for an item (subgroup, group), the sums of those cost elements are calculated, which are specified in algorithm by all main items of given subgroup (expenses subgroup of given group, subgroup), which are already divided into passenger transportation, luggage and freight baggage transportation, mail transportation according to other algorithms.

Found sums for passenger transportation (let us denote as a), luggage and freight baggage transportation (let us denote as b), mail transportation (let us denote as c) are put into above-mentioned formulas.

The methodology of passenger expenditures division into passenger transportation, luggage and freight baggage transportation and mail transportation services can provide for expenditure group, subgroup and for overhead costs items in main subgroup any of three algorithms; only first or second type of algorithm can be used for main item of expenditure.

The methodology of expenditures allocated to passenger type of movement, services for passenger transportation, luggage and freight baggage, mail makes it possible to calculate transportation prime cost for each of services.

It is worth noting that developed methodology of calculation of transportation prime cost of each of services has 
common methodical elaborations and are represented by the following methodologies:

- Methodology of division of the expenditures allocated to services (main and overhead) transportation volume independent expenditures and semi-fixed costs;

- Methodology of expenditures allocation to service measure;

- Expenditure rate calculation methodology;

- $\quad$ Service transportation manufacturing cost calculation methodology;

- Service transportation total cost calculation methodology.

Thus, we have presented methodical developments, which allow calculating the prime cost of each specific service.

Above-mentioned methodology allow calculating service prime cost value in accordance with modern requirements of financial accounting and detailing costs components and goods (passenger transportation, luggage and freight baggage transportation, mail transportation) and cost centres.

Consequently, services prime cost is defined in the form of solid tensor, dimensions of which are cost elements, transportation process' participants and prime cost dependence on transportation volume (prime cost dependent and semi-constant parts).

We interpret measures as the consolidated units of measurement that help to calculate amount of work completed on passenger transportation by the structural subdivisions of Russian Railways JSC.

Thus, passenger transportation technological process will allow identifying the system of measures for quantitative evaluation of various characteristics of transportation process.

It should be emphasized that by means of measures the very bulk properties of transportation work are identified, i.e. measures' values increase in direct ratio to transportation volume.

Functional analysis of transportation process and Russian Railways JSC structural subdivisions' participation (transportation process' participants) allowed identifying the following measure of works for each of transportation service.

For each of "FPK" JCS transportation service work measures are identified, particularly:

- $\quad$ By passenger transportation - 23 measures, among them direct measures of passenger economy:

- A departed passenger (mode of transport: long-distance traffic, suburban traffic),

- Passenger carriage-mileage in passenger traffic (carriage type: sleeping carriage, compartment carriage, open-plan carriage, public, RIC, Interregional),

- Car-hours of working fleet of passenger carriage (carriage type: sleeping carriage, compartment carriage, open-plan carriage, public, RIC, Interregional; carriage ownership: carriage in "FPK" JSC ownership, carriage in other railway ownership).

By mail transportation - 18 measures, among them only one measure represents passenger economy: departed mail car.

The measures of other economies are the same for all specified transportation services in passenger traffic.

The methodology of main expenditure items allocation to service measure defines for each measure a list of main expenditure items and a share of each element of expenditure in them, which are allocated to the given service measure.

At this point one item can be applied to several measures, but for each cost element the sum of shares applied to different measures cannot be bigger for each item.

The criterion of dependence on workload is the presence of direct dependence on workload and the frequency of work performed depending on the transportation volume which cost centres includes.

According to the developed methodology, when allocating expenditure short-term (annual) period of their accounting is considered, as well as such factors, subject to enterprise's accounting policy, as wage system, etc. (Europe 2020: a strategy for smart, sustainable and inclusive growth, European Commission. - Brussels, 2010).

The following are applied to expenditures dependent on transportation volume:

- Service expenditures, rolling stock maintenance (electric trains, diesel trains, carriages), except roundhouse servicing and overhaul, run frequency of which one exceeds one fiscal year; 
- Materials, fuel, electric power expendable in the course of transportation.

The semi-constant expenditures are the following:

- $\quad$ Rolling stock and other fixed production-related assets depreciation;

- $\quad$ Roundhouse servicing and overhaul expenditures.

The shares of expenditure item cost elements allocation to a specific measure should be substantiated by the results of R\&D works of many-years and should be regularly corrected depending on changed economic conditions (Tereshina, N. P.).

Upon main expenditure items allocation to workload measures it is necessary to allocate overhead costs in pro-rata share as well.

However, because of the complicacy of overhead costs determination corresponding to each item of main expenditures, the methodology of overhead costs division into dependent and independent parts is used, and further when calculating expenditure rates, overhead costs percent are added to each item of main expenditures by the methodology.

The methodology of overhead costs division into dependent and semi-constant parts determines the mechanism of overhead costs group items division algorithm into dependent and independent parts.

The basic principle of overhead costs division into dependent and semi-constant parts is the following principle: if within the expenditure group (subgroup) the sum of the cost element "Salary" by all dependent main expenditure items is equal to 0 , the sum of all dependent overhead costs of this group (subgroup) is also equal to 0 , i.e. if in dependent items there is no cost element "Salary", all overhead costs of this group (subgroup) are semi-constant.

This principle guarantees that if all main items of some expenditure group are referred to semi-constant part, all overhead items are also referred to semi-constant part.

If the stated principle guarantees the presence of dependent overheads, all items in the group of overhead costs are divided into three items:

- Completely dependent on the amount of traffic;

- Completely independent on the amount of traffic;

- $\quad$ Partially dependent on the amount of traffic.

From the mentioned above techniques of the methodology of cost allocation to measures of types of transportation and methodology of overhead costs division into dependent and semi-constant parts the following algorithm for expenditure division into passenger transportation independent on the amount of traffic and semi-constant parts is resulted.

Let us examine the algorithm for expenditure division into dependent and semi-constant parts:

- $\quad$ All main expenditure items are divided into measures and main subgroups of expenditures according to the method of cost allocation. If the sum of main items doesn't coincide with main subgroups, the rest part is divided in proportion to divided items sum;

- $\quad$ All overhead costs are divided at the $5^{\text {th }}$ level, if the dependent part by all main items of current main subgroup is equal to 0 , the item of overhead costs in current subgroup is completely allocated to semi-constant part, and if dependent part by all main items of current main subgroup is more than 0 , overhead costs at the $5^{\text {th }}$ level are divided according to the method of overhead costs division into dependent and semi-constant parts.

Sub-items (at the $4^{\text {th }}$ level) of overhead costs items are divided according to the vertical internal financial control based on the divided items of the $5^{\text {th }}$ level. If the sum of the items of the $5^{\text {th }}$ level turns to be less than the sub-item of the $4^{\text {th }}$ level, the excess part is divided in proportion to the sum of divided sub-items of the $5^{\text {th }}$ level, given that even one sum of dependent or independent part by all items of the $5^{\text {th }}$ level in current overhead cost item is more than 0 .

If the sum of dependent and independent parts by all items of the $5^{\text {th }}$ level in current overhead cost item is equal to 0 , the excess part is divided in proportion to coefficients $\alpha_{j}=\left(\alpha_{j 1}, \alpha_{j 2}, \ldots, \alpha_{j 9}\right)$ and $\beta_{j}=\left(\beta_{j 1}, \beta_{j 2}, \ldots, \beta_{j 9}\right)$, found when dividing the subgroup of overhead costs of current group. Subsequently, the item of overhead costs 
in main subgroup is divided in the same way.

1. All overhead items are divided at the 4th level - first according to horizontal internal control, then remaining part is either completely referred to semi-constant part, or being divided into dependent and semi-constant parts according to the algorithm for overhead costs division.

The choice of one of two algorithms depends on the presence of main expenditures even in one main subgroup of current main group, i.e. if the sum of "Salary" element by all expenditure items (of the 3rd level) of current group (if the sum of the "Salary" element by all main subgroups of current group) in their dependent part is more than 0 , the item (at the 4th level) in the subgroup of overheads costs in main group is divided according to the algorithm for overhead costs division, and if it is equal to 0 , all items at the 4th level are referred to semi-constant part.

2. Let us divide all overhead costs at the 3rd level according to horizontal internal control, then the remaining part is divided into dependent and semi-constant parts according to the algorithm for overhead costs division.

If the sums of dependent and semi-constant parts of divided overhead items are equal to 0 , the subgroups of overhead costs groups are divided according to the following algorithm.

Firstly, we need to determine whether in this subgroup there are items referred to dependent part. If there are no such items, the subgroup is completely referred to semi-constant part, if there are such items, the sums of the "Salary" element of dependent and semi-constant parts by all main subgroups of "Main production" expenditure are calculated and two "Salary" and "Deductions" cost elements are divided in proportion to calculated amounts of dependent and semi-constant parts, and all remaining elements are referred to semi-constant part.

We divide the group of overhead costs by divided subgroups according to vertical internal financial control, and the remaining part - in proportion to divided overhead subgroups sum.

If dependent and semi-constant parts of divided subgroups are equal to 0 , the group of overhead costs is divided according to the same algorithm described above for the subgroup of overhead costs.

Then we calculate shares of dependent $\alpha=\left(\alpha_{1}, \alpha_{2}, \ldots, \alpha_{9}\right)$ and independent $\beta=\left(\beta_{1}, \beta_{2}, \ldots, \beta_{9}\right)$ overhead costs in the group of overhead costs (element-by-element) by the divided group of overhead costs. Obviously, $\alpha_{1}+\beta_{1}=1$, for each $i$, if only the $i$-th cost element of the subgroup of overhead costs doesn't equal to 0 . If the first or second element is equal to 0 , then we should take shares proportional to previously calculated sums as $\alpha_{1}$ and $\beta_{1}, \alpha_{2}$ and $\beta_{2}$, and all remaining $\alpha_{i}=0$ and $\beta_{i}=1$.

Let us divide all subgroups in overhead subgroups within main groups according to vertical internal financial control, and remaining part in proportion to $\alpha$ and $\beta$ shares. Let us divide all subgroups of overhead costs within main groups in the same way. For each subgroup of overhead costs $j \quad$ (or that is the same for each main group

$j$ ) we calculate dependent of $\alpha_{j}=\left(\alpha_{j 1}, \alpha_{j 2}, \ldots, \alpha_{j 9}\right)$ and independent $\beta_{j}=\left(\beta_{j 1}, \beta_{j 2}, \ldots, \beta_{j 9}\right)$ shares of overhead costs.

1. Let us divide all subgroups of overhead costs items within main subgroup in main group $\mathrm{j}$ according to vertical internal financial control from the 5 th level to the 4th level, and remaining part in proportion to $\alpha j$ and $\beta_{\mathrm{j}}$.

2. Let us divide all main expenditure groups according to vertical internal financial control, and remaining part - in proportion to the divided part.

In the context of the model expenditure rates are divided into dependent and semi-constant expenditure rates.

The sums of dependent and semi-constant expenditure rates are called complete expenditure rates.

Specific measures are identified for each of services - "passenger transportation", "luggage and freight baggage transportation", "mail transportation" - i.e. measures are consolidated measurement units for quantitative evaluation of various characteristics of transportation process.

It should be emphasized that by means of measures the very bulk properties of transportation work are identified, i.e. measures' values increase in direct ratio to transportation volume.

The proposed methodology of semi-constant expenditures allocation to work measures is based on the method of main expenditure items allocation to measures and mainly corresponds to the following idea: the more dependent 
expenditures per measure, the more semi-fixed costs referred to this measure should be.

Before we turn to the algorithm of expenditures rate computation, Let us note the following:

- When calculating expenditures rates only "Main Production" expenditure items of the range are used;

- When calculating expenditures rates overhead costs items don't participate, only overhead costs subgroups participate.

The methodology of the allocation of costs allocated to the passenger type of movement, passenger transportation service, luggage and freight baggage transportation, mail transportation allows calculating these services' prime cost.

We have examined conceptual approaches, which subsequently allow calculating the prime cost of each specific service of "FPK" JSC.

It is commonly known that each measure characterizes (measures) the work of only one participant of transportation process in contrast to common approaches (expenditure rates method), wherein the expenditures of several economies can be allocated to one measure, i.e. measure practically act as a unit of work performed by several economies (Belenky, A. S., Rezer, S. M., \& Yunusova, A. I.).

Notice that the tree of transportation process economies-participants measures at the $1^{\text {st }}$ level consists of measures of these economies' work main indicators, and at the remaining levels - sub-measures, which reflect dependence on the value of corresponding factors. We'll use this dependence when calculating specific service's prime cost with due account for factors.

The period expenses allocation by measures allows generating matrix of measures' specific volumes per $1 \mathrm{car}$ kilometre for each service regarding passenger transportation, luggage and freight baggage transportation, and mail transportation.

Matrix chart shown in Table 1 makes it possible to calculate passenger transportation prime cost.

Table 1. Matrix chart for passenger transportation prime cost calculation

\begin{tabular}{llll}
\hline Work measures & Measures volume & Expenditure rates & $\begin{array}{l}\text { Measures' specific volume per 1 } \\
\text { car kilometre }\end{array}$ \\
\hline 1 & & & $\mathrm{D}_{1}$ \\
$\ldots$ & $\mathrm{V}_{1}$ & $\mathrm{R}_{1}$ & $\ldots$ \\
$\mathrm{i}$ & $\ldots$ & $\ldots$ & $\mathrm{D}_{\mathrm{i}}$ \\
$\ldots$ & $\mathrm{V}_{\mathrm{i}}$ & $\mathrm{R}_{\mathrm{i}}$ & $\ldots$ \\
$\mathrm{m}$ & $\ldots$ & $\ldots$ & $\mathrm{D}_{\mathrm{m}}$ \\
\hline
\end{tabular}

where $V_{i}-\quad$ the $i-t h$ measure's volume;

$R_{i} \quad-\quad$ expenditure rate of $i-t h$ measure;

$D_{i} \quad-\quad i$-th measure's volume, per 1 car-kilometre.

We present the production cost computation algorithm of "FPK" JSC, medium- network prime cost calculation.

1. Calculation of workload (measures' values) per car kilometre.

$$
D_{i}=\frac{V_{i}}{n s}
$$

where $V_{i}$ - the volume of the $i$ - measure of service;

$n s$ - car-mileage in passenger traffic regarding this service.

2. Calculation of the railroad transportation net cost of transportation service: summing up of products of measures' expenditure rates by corresponding measures' specific volumes per car kilometre

$$
D=\sum_{i=1}^{n} D_{i} R_{i}
$$

where $D_{i}-i$-measure's volume per car kilometre; 
$R_{i}$ - expenditure rate of the $i$-measure.

Thus, the found prime cost of each of services (passenger transportation, luggage and freight baggage transportation, mail transportation) is defined in the form of solid tensor, dimensions of which are cost elements, transportation process' participants and prime cost dependence on transportation volume (prime cost dependent and semi-constant parts).

The methodology of service prime cost calculation with due account for factors allows calculating service's prime cost with due account for the following factors:

- Transportation mode,

- Type of carriage,

- Type of haulage,

- Class of train,

- Carriage ownership.

For each of chosen factor's values a matrix of volumes per 1 car-kilometre is constructed.

Transportation service prime cost computation algorithm with due account for factors is the following:

1. Calculation of workload (measures' values) per 1 car-kilometre.

- In case a measure is dependent on factors $\left(h_{1}, h_{2}, \ldots, h_{k}\right)$, the measure's volume, per 1 car-kilometre, is found according to the formula:

$$
D_{i}=\frac{V_{i}\left(g_{1}^{j_{1}}, g_{2}^{j_{2}}, \ldots, g_{l}^{j_{l}}\right)}{n s\left(g_{11}^{j_{1}}, g_{2}^{j_{2}}, \ldots, g_{l}^{j_{l}}\right)},
$$

where $V_{i}\left(g_{1}^{j_{1}}, g_{2}^{j_{2}}, \ldots, g_{l}^{j_{l}}\right)$ - volume of the $i$-measure of service with due account for factors;

$n s\left(g_{1}^{j_{1}}, g_{2}^{j_{2}}, \ldots, g_{l}^{j_{l}}\right)$ - car-mileage with due account for factors;

$\left(g_{1}, g_{2}, \ldots, g_{l}\right)=\left(h_{1}, h_{2}, \ldots, h_{k}\right) \cap\left(f_{1}, f_{2}, \ldots, f_{n}\right)$.

i.e. factors to calculate net cost are found as a crossing measures' factors $\left(h_{1}, h_{2}, \ldots, h_{k}\right)$ and the "car-mileage" factor $\left(f_{1}, f_{2}, \ldots, f_{n}\right)$, in case a measure is independent on factors, we should take consolidated measure volume as a measure volume (without regard to factors) and, correspondingly, the value of "car-mileage" measure is stated without regard to the factor

$$
D_{i}=\frac{V_{i}}{n s},
$$

where $V_{i}$ - the volume of the $i$-measure of service;

$n s$ - car-mileage in passenger traffic regarding the service.

We give an example on application the above-mentioned mechanism for calculating "passenger transportation" service net cost with regard to the "long-distance traffic" factor.

When generating matrix, we specify the volume of the "departed passenger in long-distance traffic" sub-measure as a measure's volume, and "passenger car-mileage in long-distance traffic" as a denominator, etc.

Therefore found measures' volumes allow calculating given measure's specific volume per 1 car-kilometre for the "long-distance traffic" factor value.

If there is no dependence on the "transportation mode" factor for a measure, for example, a measure is "prepared carriage", in this case the volume of the consolidated measure "prepared carriage' is specified to find specific volume per 1 car-kilometre, and the volume of "car-mileage in passenger traffic" measure is specified in the denominator.

2. Passenger railroad transportation net cost calculation: the summing up of products of measures' expenditure rates by corresponding measures' specific volumes per car kilometre 


$$
D=\sum_{i=1}^{n} D_{i} R_{i},
$$

where $D_{i}$ - the volume of the $i$-measure per 1 car-kilometre;

$R_{i}$ - expenditure rate of the $i$-measure.

As we know, in dependence on what expenses are considered when calculating net cost, there are production and total cost. Production cost is calculated only on the base on transportation costs, and when calculating total cost also period expenses allocated to transportation are considered.

Thus, in order to find total cost it is necessary to determine production cost with period expenses, which include

- Administrative expenses;

- General running costs of production nature;

- Taxes and charges paid at the expense of company's income;

- Interest expenses.

We introduced changes in planning procedure and analysis of passenger carriage use qualitative indicators, such as occupancy and degree of utilization, average daily mileage, and passenger carriage performance set on the route of carriage running.

"FPK" JSC income includes:

- Passenger, luggage and freight baggage, mail transportation revenues;

- Additional income related to transportation and passenger service, bedding items and tea sales income;

- Earnings from secondary supporting activities and material assets sales -repair and maintenance of carriage belonging to outside organizations and structural subdivisions of Russian Railways JSC, wheel pairs repair, dining car products;

- Earnings from non-core activities - carriage, equipment and production premises rent.

"FPK" JSC expenditure pattern is shown in Figure 2 and 3.

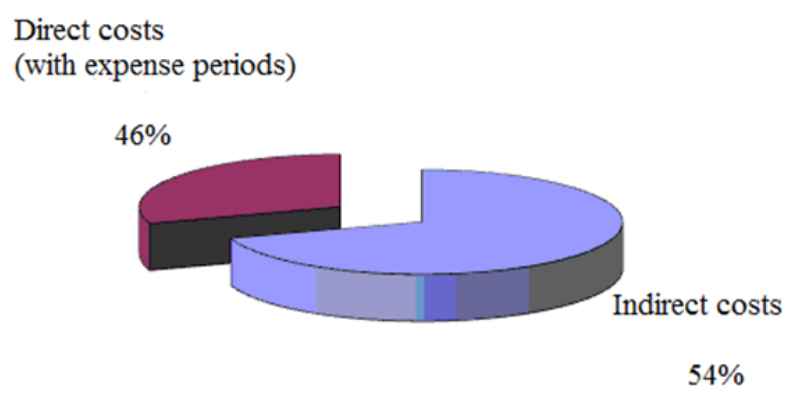

Figure 2. "FPK" JSC direct and indirect costs structure

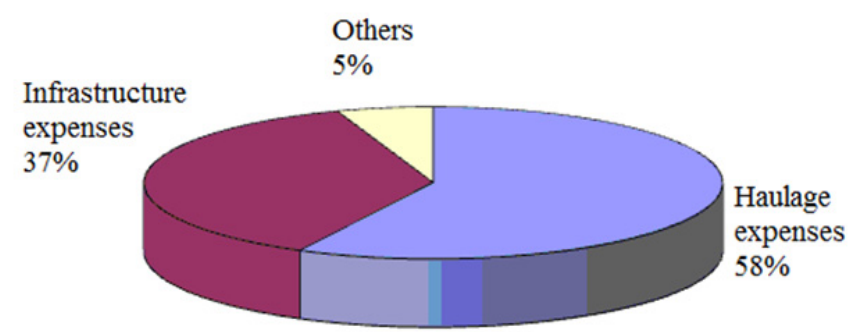

Figure 3. "FPK" JSC infrastructure and haulage indirect costs structure 
In the structure of indirect costs locomotive economy expenses account for $58 \%, 37 \%$ fall at main route keeping, $5 \%$ - other expenses (arrangement of transportation).

"FPK" JSC direct costs are all remaining expenses coming from providing passenger transportation which are reflected in their own balance and comprise $46 \%$ of all expenses.

Salary fund and social expenditures comprise the main part of direct costs $-35,3 \%$, payment for work and services - 17,2\%, materials expenses - $14,2 \%$.

Expense budget increase is connected to:

- Increase in passenger carriage overhaul volume, including overhaul on outsourced plants;

- Average monthly salary increase;

- Billings regarding communications services, wheel pair repair, etc., related to the switch to contractual arrangements between the enterprises of Russian Railways JSC.

FPK" JSC direct costs pattern is shown in Figure 4.

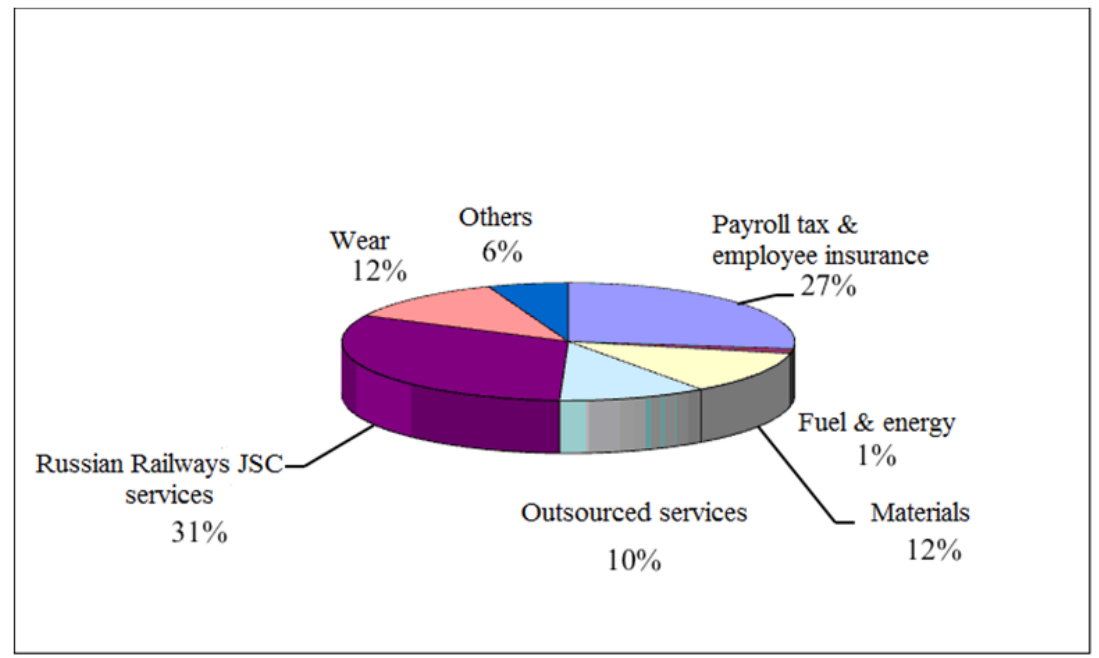

Figure 4. "FPK" JSC direct costs pattern

The structure of direct costs in terms of economies and types of activity of "FPK" JSC is shown in Figure 5. It is observed that the major share falls at long-distance traffic and short distance traffic.

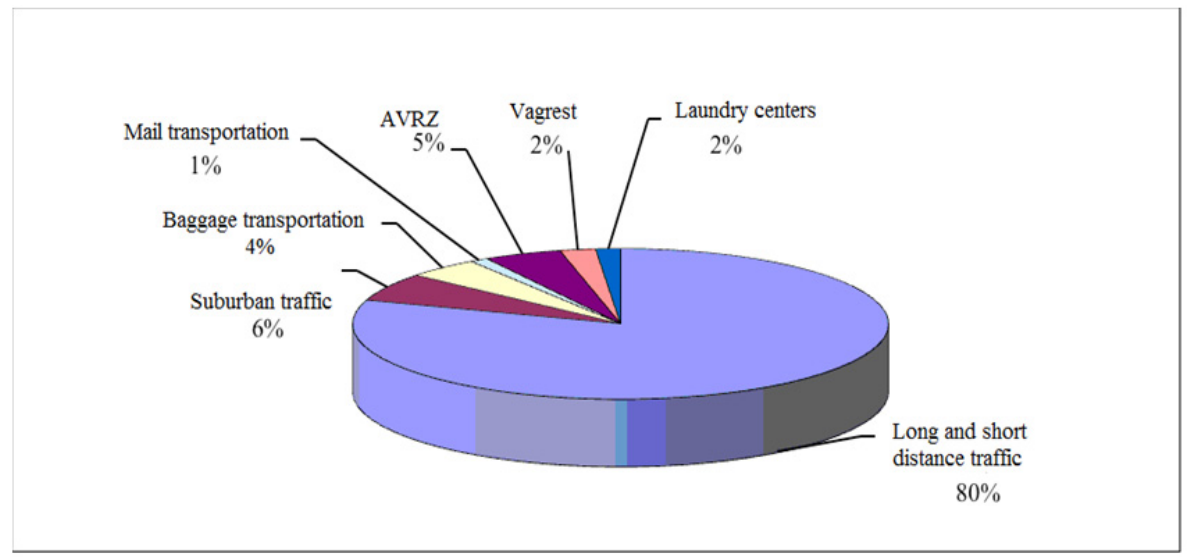

Figure 5. The structure of direct costs regarding the types of transportation and business activities of "FPK" JSC

The question of a measure for which payments will be collected for access to backbone railway network (BRN) was discussed for a long time. Main lines' operator is a main participant of transportation process, who connects the transportation technology process in integral whole.

Owing to the importance of equal access to information on rendered services for all users, main lines' operator 
annually announces time-schedule made up together with transporters and other concerned clients. Using this document each transporter gets information on train paths where he can move his trains.

According to the list of expenses and operator's main function regarding freight and passenger traffic safety ensuring along the route the cost of service to access main lines includes all expenses of the following facilities: car check stations and freight commercial examination stations, main computer center, track station, signal system and connections, power supply.

Formulas for main lines' operator's services computation and traffic factors are represented in Table 2.

Table 2. BRN operator's services

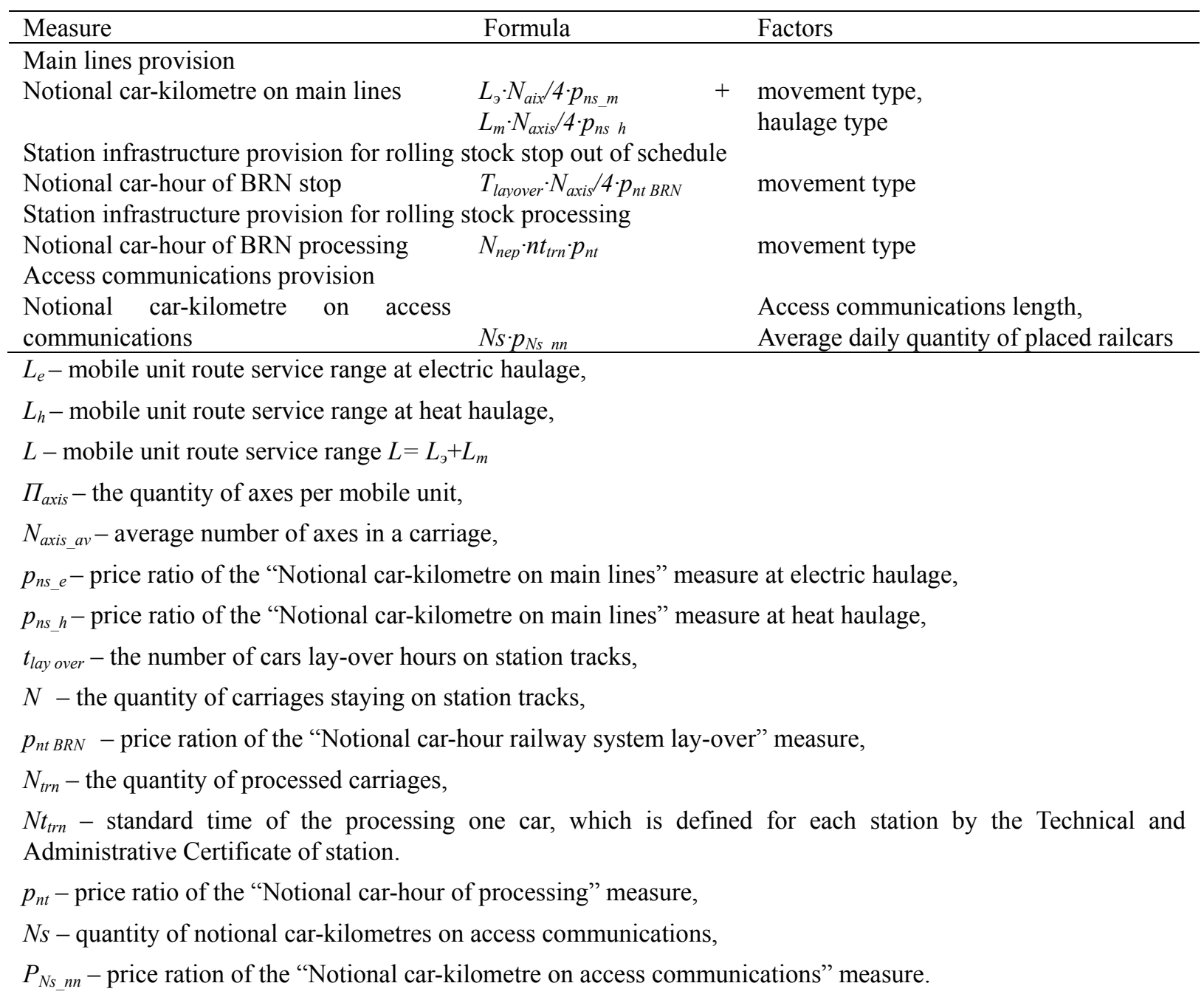

The tariff for access to main lines is set for provision and passes by main and station infrastructure to rolling stock operators and transporters when executing freight and passenger transportation.

According to this definition in expense side the tariff includes labour costs, materials and power resources consumption, repair expenses, keeping and depreciation of fixed assets when rendering given service.

Moreover, main infrastructure is a property of state, which is interested to receive dividends of main lines income and it prefers to allot main lines incomes regardless of operator's internal policy.

According to established rate for access to main lines, it is also true for clients, who transport the same cargo weight on different amount of carriages or passenger-trains with different formation.

Let us examine the methodology for detecting the rate of transporter's expenditures by the types of "FPK" JSC rolling stock. 
This methodology for detecting the rate of expenditures of "FPK" JSC by the types of rolling stock allows establishing the procedure for computing the rate of transporter's expenditures composed of passenger carriages and motor-carriage rolling stock for monthly billing to customers of socially important suburb routes according to concluded contracts.

The source of information used in computing is monthly accountant software form.

The statement of expenditures is formed according to expenses nomenclature of rail transport enterprises, where expenses relating to passenger carriages and motor-carriage rolling stock are allocated to related accounts and expenditure items.

The rate of expenditures by motor-carriage rolling stock (A) is found according to the formula:

$$
A=(C+E) / Z \quad \text { in rub, }
$$

where $\mathrm{A}$-the rate of expenditures by motor-carriage rolling stock;

$\mathrm{C}$ - transportation expenses (direct + overhead);

$\mathrm{E}$ - period expenses relating to motor-carriage rolling stock in proportion to car-kilometres;

$\mathrm{Z}$ - the amount of car-kilometres, which fall on motor-carriage rolling stock traffic for passenger transportation.

The rate of expenditures by passenger carriages $(\mathrm{B})$ is determined from the formula:

$$
B=(D+F) / I \text { in rub, }
$$

where $\mathrm{B}$ - the rate of expenditures by passenger carriages;

$\mathrm{D}$ - transportation expenditures (direct + overhead);

$\mathrm{F}$ - period expenses relating to passenger carriages in proportion to car-kilometres;

I - the amount of car-kilometres, which fall on passenger carriages traffic for passenger transportation.

Transportation expenses (direct and overhead) are collected separately by sub-accounts, which reflect expenses by motor-carriage rolling stock (C) and passenger carriages (D) net of payment expenditures for access to BNR and locomotive haulage, which are determined by reconciliation statements and invoices for relevant period.

Given that, information services and payment for access to platforms should be allocated in proportion to the number of layovers per motor-carriage rolling stock and passenger carriages.

The total amount of period expenses is allocated to motor-carriage rolling stock (E) and carriages (F) in car-kilometres proportion.

Period expenses relating to motor-carriage rolling stock $(\mathrm{E})$ are calculated according to the following formula:

$$
E=Z / G * K \text { in rub, }
$$

where $\mathrm{G}$ - total passenger car-mileage "FPK" JSC wide;

K - period expenses "FPK" JSC wide.

Period expenses relating to passenger carriages (E) are calculated according to the following formula:

$$
E=I / G * K \text { in rub, }
$$

where $\mathrm{G}$ - total passenger car-mileage and MCRS (motor-carriage rolling stock)

$\mathrm{K}$ - expenses period "FPK" JSC wide;

$\mathrm{G}=\mathrm{Z}+\mathrm{I}$ - total passenger car-mileage and MCRS.

The information source of passenger and motor-carriage rolling stock car-mileage is

“FPK" JSC participants' report by passenger and motor-carriage rolling stock car-mileage, passenger carriage report, MCRS report.

The examined methodology for mail service cost computation by railroad transport accompanied by the employees of mail organizations in passenger carriages in "FPK" JSC ownership is developed in accordance with the rules of mail carriage and passenger carriages operations on railway of the Russian Federation for the purpose of establishing uniform procedure for mail service cost formation.

Mail transportation services in passenger carriages in "FPK" JSC ownership is paid by main organizations according to "FPK" JSC performed settlement based on concluded contracts or filed request. 
Payment of mail transportation services accompanied by post organizations' employees is calculated according to the following formula:

$$
\mathrm{S}=\mathrm{B}+\mathrm{L} \text {, at that } \mathrm{B}=\mathrm{k} * 0.1 * \mathrm{v} * \mathrm{p} \text {, and } \mathrm{L}=\mathrm{m} * \mathrm{n},
$$

where $\mathrm{S}$ - total charge of mail transportation accompanied by mail organization's employees;

$\mathrm{B}$ - luggage transportation charge;

$\mathrm{L}$ - fare of mail accompanying people;

$\mathrm{k}$ - number of places for main transportation;

0,1 - coefficient according to rules;

$\mathrm{v}-\mathrm{car} / \mathrm{km}$ rate when transporting mail;

$\mathrm{p}$ - distance;

$\mathrm{m}$ - fare per 1 person;

$\mathrm{n}$ - the number of accompanying mail organization's employees.

When calculating service cost we take planned traffic volume as a base, according to filed request or concluded contracts. In case of mail volume change, real volume of service performed is taken as a base.

Along with "FPK" JSC, private carriers function in regional centres.

Private carriers arranged transportation with full payment of BRN service.

\section{Results}

In transport economy the elasticity of demand for transportation is of great importance. There are three variants of transport company's policy implementation in dependence on the activity goals:

- Social welfare policy focused on maximizing profit for transport company's services' users;

- Similar variant with budgetary limitations (subsidies use limit);

- Transporter's profit maximization variant.

Let us examine alternatives in mathematical representation, assuming that demand function $(Q)$ depends solely on passenger fare in trains $(p)$.

Bottom-line social benefit maximization in the context of transporter's activity

$$
N S B=\int_{0}^{O} Q^{-1}(q) d q-C(q),
$$

where $Q^{-1}(q)$ represents inverse demand function.

$C(q)$ - transporter's cost function.

First-order condition provides that to calculate extremum value the first-order derivative of goal function should be equal to 0 , i.e.

$$
\begin{aligned}
& Q^{-1}(q)-\frac{d C}{d q}=0 \\
& Q^{-1}(q)=\frac{d C}{d q} \\
& p=M C
\end{aligned}
$$

Thus, cost of one passenger transportation (p) should be equal to marginal costs $(M C)$, necessary for this passenger travel organization. This equality is a widespread postulate of economic policy of maximizing social welfare.

Maximization of bottom-line social benefit (NSB) involving budgetary limitations can be expressed by the following expression:

$$
\text { Maximize } N S B=\int_{0}^{Q} Q^{-1}(q) d q-C(q),
$$

given that income net of transporter's operation costs is equal to fixed amount, which characterizes maximum 
level of subsidies $\pi$, i.e. $p Q(p)-C(Q)=\pi$

Using for this expression Lagrange multiplier method, we get the following expression:

$$
L=\int_{0}^{Q} Q^{-1}(q) d q-C(q)+\lambda[(p Q(p)-C(Q)-\pi]=0
$$

Applying first-order condition we have:

$$
\begin{aligned}
& Q^{-1}(q)-\frac{d C}{d q}+\lambda\left[\left(p-\frac{d C}{d q}\right) \frac{d Q}{d p}+Q(p)\right]=0 \\
& p(Q)=M C+\lambda\left[(p-M C) \frac{d Q}{d p}+Q(p)\right]
\end{aligned}
$$

Thus, transportation fare should be higher than marginal costs (MC) per value, specified in the right side of the last equation, where $\lambda$ represents shadow price of one additional measurement unit of social benefit at one used unit (rub) of subsidies.

The policy of profit maximization can be represented in the following form:

$$
p Q(p)-C(Q)=>\max ,
$$

The use of first-order conditions allows us to have the following expression:

$$
\begin{aligned}
& p(Q) \frac{d Q}{d p}+Q(p)-\frac{d C}{d q} \frac{d Q}{d p}=0 \\
& (p-M C) \times \frac{d Q}{d p}=-Q(p) \\
& p-M C=-\frac{Q(p)}{d Q / d p} \quad \text { elasticity } e=\frac{p}{Q(p)} \frac{d Q}{d p}, \text { and } \frac{d Q}{d p}=e \frac{Q(p)}{p}, \text { therefore: } \\
& p+\frac{p}{e}=M C \\
& p\left(1+\frac{1}{e}\right)=M C=M R
\end{aligned}
$$

Thus, as a result of profit maximization policy use the cost should be equal to marginal revenue.

The example of settled computations stresses the need for knowledge of freight and passenger market basic parameters, based on the interaction of supply and demand.

Such approach will allow adopting decisions based on scientifically grounded principles for the benefit of specific price policy and different variants of carriers' operations regulation.

In the usual sense demand depends on quotation for goods, however, a rule of thumb states that many factors, including macroeconomic, social and economic, financial and others indicators, influence demand (Galaburda, V., Abramov, A., \& Ivanova, E.).

The author constructed the following econometric model:

$$
\ln Q=\propto_{0}+\beta_{F} \ln F+\beta_{P} \ln \left(P_{1}+P_{\mathrm{f}}\right)+\beta_{I} \ln \left(I_{1}+I_{\mathrm{f}}\right)+\beta_{S} \ln S+\beta_{U} \ln U+\sum_{K=1}^{11} \beta_{K} D_{K}
$$

where:

$Q$ - demand for transportation, passenger-kilometre;

$F$ - average fare (revenues per 1 passenger-kilometre.), rub;

$P_{1}, P_{j} P_{i}, P_{j}-$ population in departure and destination zones, person;

$I_{1}, I_{\text {f }}$ average salary of one employs in departure and destination zones, Rub;

$S$ - frequency of trains running (car-kilometre / route length);

$U$ - train average speed, $\mathrm{km} / \mathrm{h}$.;

$D_{i}-D_{i}$ the system of fictitious variables, which adopt a value 1 in a specific month and 0 in other cases; $u_{\mathrm{k}}, \beta_{i}$ $\alpha_{0}, \beta_{i}-$ coefficients. 
The author carried out heteroscedasticity test according to Breusch-Pagan test (Gomez-Ibanez J. and de Rus G., 2006).

Assuming that error variance is a linear function of all non-stochastic exogenous variables $(Z)$, all independent variables can exercise a function of the $\mathrm{Z}$ variable, therefore the following model is formed.

$$
o^{2}=a_{u}+a_{\mathrm{j}} \ln F+u_{P} \ln \left(P_{i}+P_{\mathrm{f}}\right)+u_{I} \ln \left(I_{i}+I_{\mathrm{j}}\right)+u_{S} \ln S+a_{U} \ln U+\sum_{K=1}^{11} \beta_{K} D_{K}
$$

To confirm that $\sigma^{2}$ is homoscedastic, a hypothesis is suggested that $\alpha_{1}=\alpha_{2}=\alpha_{3}=\ldots .=\alpha_{15}=0$ (or that $\sigma^{2}=\alpha_{0}=$ const $)$, the consistence of which was tested.

The method implementation algorithm:

1) Using the values of the found excesses $\hat{u}_{1}, \hat{u}_{2}, \hat{u}_{3}, \ldots . \hat{u}_{n}$ the following value was formed $\tilde{\sigma}^{2}=\frac{\sum_{i=1}^{n} \hat{u}_{i}}{n}$.

2) Then the following variable was formed: $\quad p_{i}=\frac{\bar{u}^{2}}{\hat{o}^{2}}$

3) The regressive analysis of $p_{i}$ value by known variables was carried out:

$$
p_{2}=a_{o}+a_{\mathrm{f}} \ln F+u_{P} \ln \left(P_{i}+P_{\mathrm{j}}\right)+u_{\mathrm{j}} \ln \left(I_{i}+I_{\mathrm{j}}\right)+u_{S} \ln S+a_{U} \ln U+\sum_{K=1}^{11} \beta_{K} D_{K}
$$

4) Using the findings of explained part of total variance (ESS) the following value was defined $\Theta=\frac{1}{2}(E S S)$.

Assuming that the value of $u_{i}$ is normally distributed, the sample volume increases infinitely and there is homoscedasticity, the found value $\Theta$ should follow to the pattern of chi-square $\left(\chi^{2}\right)$ with $(m-1)$ degree of variance.

Thus, if calculated value $\Theta$ exceeds critical value $\chi^{2}$, the hypothesis on the homoscedasticity presence can be rejected.

The found value $\Theta$ is equal to 23,52 for all types (without considering luxury sleeping carriages and third-class sleepers), given that, critical value $\chi^{2}$ for data base with 15 degrees of variance comprises 24,99 , i.e. the found value doesn't exceed critical one.

Thus, null hypothesis that $\alpha_{1}=\alpha_{2}=\alpha_{3}=\ldots=\alpha_{15}=0\left(\sigma^{2}=\right.$ const $)$ cannot be rejected with the statistical validity of $5 \%$ and the test proves that errors resulted in the course of our models analysis are constant and there is no heteroscedasticity.

The conducted assessment via least squares technique is linearly unbiased and asymptotically (in case of large sample volume) normally distributed at main assumptions (Gujarati, D. N., \& Studenmund, A. H.).

Assuming that 300 examinations can be considered sufficiently large sample, the model demonstrates representation of all main parameters.

Otherwise, it is necessary to expand sample and/or transform the model for the purpose of more detailed reflection of dependences between outcome variable and the system of regressors, as well as inconstancy in variables' errors' factors. 
Thus, to enhance the effectiveness of the passenger transportation process arrangement it is necessary to increase the level of the scientific substantiation of adopted decisions and to develop advanced proposals regarding this segment of economy based on scientific approaches. Considering the large involvement of the state in this process, concerned public authorities with the assistance of scientific potential and branch companies for adopted decisions implementation should become the main initiators of all changes.

\section{Conclusions}

"FPK" JCS represents liberalized market of transport railway services, wherein the conditions for independent carriers operations, which use backbone railway network services, are created.

The strategic program for railroad transport development for the period to 2020 provides passenger transportation development with the participation of state, domestic corporation, and private carriers. Moreover, the execution of socially important passenger transportation based on long-term agreement of public-private partnership is provided.

With regard to the enhancement of the proposed model for passenger transportation operation, which provides their commercial appeal at the expense of state subsidies, the policy of Russian Railways JSC in the area of passenger transportation should include

- Passenger complex assets restructuring;

- Passenger carries operation's refocusing to commercial principles.

To meet set goals "FPK" JSC business should be conducted based on Russian Railways JSC business strategy, in the framework of which it is necessary to segment services by profitability, define marketing goals by segments and market shares, as well as measures regarding increase in operating and cost effectiveness.

The proposed methodology of passenger transport management based on the econometric analysis of demand for trans-regional passenger transportation will contribute to:

- Scientific component strengthening in current and prospect activity of the branch increases expenses for research activities in government budget;

- Transporters' losses funding principles change with regard to adequate profitability, allocation of fresh funds for rolling stock fleet renewal that requires own regular researches by government agencies of the RF in order to study the demand for transportation and estimate real needs for passenger railway transport services;

- Improving regulatory framework for passenger transportation arrangement based on long-term agreements with clear obligations of parties regarding the increase in service for passenger and adequate payment on the part of the state;

- Statistic base expanding at the expense of transport market regular researches, including social mobility analysis and its influencing factors analysis;

- Strengthening measures regarding monitoring compliance with contractual commitments and prevention of violation on the part of carriers, since it is important to have feedback on the part of passenger concerning their satisfaction with service, for which nationals pay twice: when buying tickets and paying taxes.

\section{References}

Arkhangelsky, V. N. (1997). Organizational and economic problems of research study management. Moscow: Nauka, 57.

Belenky, A. S., Reser, S. M., \& Yunusiva, A. I. (2011). National and international practices of railways freight transportation tariff policy development. Transport: nauka, tehnika, upravlenie, 4, 3-11.

Elizarev, Y. V. (2014). The conceptual framework of state support system development in relation to trans-regional passenger transportation. Ekonomika Zheleznykh Dorog, 12, 15-25.

Elizarev, Y. V., \& Gorbunova, M. A. (2003). Regarding passenger fare development. Zheleznodorozhny Transport, 3, 58-60.

Europe, 2020: A strategy for smart, sustainable and inclusive growth, European Commission. Brussels, 2010.

Galaburda, V., Abramov, A., \& Ivanova, E. (2001). Marketing in transport. Moscow: Zheldorizdat, 438.

Gomez-Ibanez, J., \& de Rus G. (2006). Competition in the Railway Industry: An International Comparative Analysis, Cheltenham: Edward Elgar.

Gujarati, D. N. (2003). Basic Econometrics. McGraw Hill, International Edition. 
IBM Global Business Services, Humboldt University (Germany), RailLiberalisation Index 2007: Market opening: comparison of the rail markets of the Member States of the European Union, Switzerland and Norway, Zurich.

Kolpakov, V. S., \& Shubko, V. G. (2003). Passenger transportation enhancement. Moscow: Transport, 324.

Kuvatov, M. R. (2003). Maintenance costs impact on transportation prime cost. Economy in transit, 2, 24-28.

Macheret, D. A. (2003). The influence of transport on social and economic development. Ekonomika Zheleznykh Dorog, 11, 19-24.

Office of rail regulation, Promoting safety and value in Britain's railways: Our strategy for 2009-2014. London, 2008.

Railway transport economy (2013). Textbook: for railway transport universities. In Andreev B. F. et al., (Eds.), Moscow: Railway transport training center: PR-Press. 533.

Sklyarenko, V. K., \& Prudnikov, V. M. et al. (2009). Company Economics: Study guide (in diagrams, tables, computations). Moscow: Finansy i statistika, INFRA-M, 256.

Studenmund, A. H. (2001). Using econometrics: A practical guide (5th ed). Pearson International Edition, Addison-Wesley, 425p.

Suraeva, M. O. (2014). The mechanism of state regulation of innovative activity of large companies / Modern innovative approaches to development of economic relations in conditions of globalization: Proceedings of the International scientific and practical conference (Yelm, WA, USA, May 2014)/ Editor in Chief Dr. Sci., Prof. O.Ja. Kravets Yelm, WA, USA 34-41.

Tiverovsky, V. I. (2013). Innovation in transport and logistics abroad. Transport: nauka, tehnika, upravlenie, 4, 17-21.

Varian, X. P. (1997). Microeconomics. Intermediate level. A modern approach. In Frolova N. L. (Ed.), Moscow: ENITY, 767.

Zamkov, O. O., Tolstopyatenko, A. V., \& Cheremnyh, Y. N. (2001). Mathematical methods in economy. Moscow: Nauka, 368.

\section{Copyrights}

Copyright for this article is retained by the author(s), with first publication rights granted to the journal.

This is an open-access article distributed under the terms and conditions of the Creative Commons Attribution license (http://creativecommons.org/licenses/by/3.0/). 